\section{$\$$ Research Square}

Preprints are preliminary reports that have not undergone peer review

They should not be considered conclusive, used to inform clinical practice, or referenced by the media as validated information.

\title{
Clinical Feeding Evaluation and Videofluoroscopy: An Integrative Approach to Feeding Management in Children With Suspected Aspiration
}

Patrick Stafler ( $\sim$ pstafler@hotmail.com )

Schneider Children's Medical Center of Israel https://orcid.org/0000-0001-8880-8212

Khaled Akel

Schneider Children's Medical Center of Israel

Yuliana Eshel

Schneider Children's Medical Center of Israel

Adi Shimoni

Schneider Children's Medical Center of Israel

Sylvia Grozovsky

Schneider Children's Medical Center of Israel

Meir Mei-Zahav

Schneider Children's Medical Center of Israel

Hagit Levine

Schneider Children's Medical Center of Israel

\section{Yulia Gendler}

Schneider Children's Medical Center of Israel

Hannah Blau

Schneider Children's Medical Center of Israel

Dario Prais

Schneider Children's Medical Center of Israel

\section{Research Article}

Keywords: Video-fluoroscopic swallow study, aspiration lung disease, overt aspiration, silent aspiration

Posted Date: February 16th, 2021

DOl: https://doi.org/10.21203/rs.3.rs-162390/v1

License: (c) (i) This work is licensed under a Creative Commons Attribution 4.0 International License. Read Full License 


\section{Abstract}

\section{Background}

Video fluoroscopy swallow studies (VFSS) are considered gold standard for the diagnosis of aspiration in children but require resources and radiation compared to clinical feeding evaluation (CFE). We evaluated their added value for diagnosis, feeding management and clinical status.

\section{Methods}

A retrospective single-center cohort study of children aged 0-18 years, referred for VFSS at a tertiary pediatric hospital.

\section{$\underline{\text { Results }}$}

113 children, median age (range) 2.2 years (0.1-17.9) successfully completed VFSS. Forty-six (41\%) had oropharyngeal aspiration, 9 (8\%) overt alone and $37(33 \%)$ including silent aspirations. Underlying medical conditions included clinically suspected aspiration lung disease (ALD), 87 (77\%); neurologic disease, 73 (64\%); gastrointestinal disease, 73 (64\%) and congenital heart disease, 42 (37\%), not mutually exclusive. Those with ALD or cerebral palsy were more likely to have aspiration by VFSS, OR 3.2 and 9.8 respectively. Sensitivity and specificity of CFE for VFSS diagnosis of aspiration were $71 \%$ and $84 \%$ respectively.

Feeding recommendations after VFSS differed significantly from those based on prior $C F E, p<0.001$ : The rate of exclusively orally fed children increased from $65 \%$ to $79 \%, p=0.006$ and exclusively enterally fed children from $10 \%$ to $14 \% ; p=0.005$. During the following year, there were significantly less antibiotic courses, as well as total and respiratory admissions.

\section{Conclusions}

In this population of children with a high prevalence of clinically suspected ALD, VFSS refined diagnosis and altered feeding management compared to CFE, with subsequent clinical improvement.

\section{Introduction}

Swallowing involves seamless co-ordination of voluntary and involuntary neuromuscular activities propagating liquid and food boluses from the mouth through the pharynx and into the esophagus. Neurologic, $(1,2)$ developmental and structural $(3,4)$ disorders are associated with swallowing dysfunction resulting in morbidity and some mortality due to aspiration of foreign material into the lung. Clinical feeding evaluations (CFE) by occupational (OT) or speech and language therapists (SLT) are important for diagnosis of swallowing disorders, swallowing training and referral for instrumental assessment. (5) The therapist inspects the face and oropharynx for anatomic abnormalities and offers different textures, while closely observing the swallowing process, auscultating for respiratory sounds, and noting voice quality, cough and respiratory distress. When symptoms are overt and improve following intervention, children are often not referred for further evaluation. 
Video fluoroscopy swallow studies (VFSS), considered the gold standard for swallowing assessment, are best performed following CFE by collaboration between the OT or SLT and the pediatric radiologist. (6) Using a variety of radiolabeled textures, information is obtained about anatomy and function, including oropharyngeal transit time, pharyngeal motility and pooling of material in the vallecula and pyriform sinuses. Although VFSS is resource intensive and involves radiation, it remains essential particularly in cases with higher morbidity or where silent aspiration (SA) without a corresponding protective cough reflex, is suspected. $(5,6)$ Recent studies suggest that CFE may not adequately predict aspiration risk in children, $(7)$ compared with VFSS. (8)

The present study aimed to determine the reliability of the CFE compared with VFSS in children, to describe the impact of CFE and VFSS on feeding recommendations and to evaluate clinical status one year post VFSS and feeding intervention, as compared to one year prior to VFSS.

\section{Methods}

\section{Study_population}

This was a retrospective single-center cohort study of children referred for VFSS at a tertiary pediatric hospital (SCMCI). Included were all children who successfully completed a VFSS between the ages of 0-18 years between the years 2011 and 2017. Excluded were children who failed the VFSS technically or due to lack of co-operation. The study was approved by the local Institutional Review Board, number 0516-17-RMC.

Medical records were reviewed and coded for chiefly affected organ systems using a modified version of Burklow et al (9) which includes structural abnormalities, neurological conditions, behavioral issues, cardiorespiratory problems and metabolic dysfunction. We did not include behavioral and metabolic categories, but added gastrointestinal and genetic categories. Affected organ systems were not mutually exclusive. We further grouped patients according to medical diagnoses, again not mutually exclusive, including Down's syndrome, cerebral palsy, developmental delay, tracheo-esophageal fistula, congenital heart disease, preterm birth (prior to 37 completed weeks), bronchopulmonary dysplasia and clinically suspected aspiration lung disease.

\section{Clinical feeding evaluation}

Following referral from hospital departments, outpatient clinics and community settings, children were assessed by an OT, and case notes were reviewed by an experienced OT for this study. The eight-point penetration-aspiration score, validated and previously used in children $(10,11)$ was simplified to facilitate comparison between CFE and VFSS (6) (table 1). For this purpose, penetration was regarded as no aspiration. Aspiration was noted separately for each texture trialed and a positive diagnosis was made if present for one or more food textures. A clinical diagnosis of suspected silent aspiration (SA) referred to anamnestic clues and subtle signs such as a wet/ phlegmy vocal quality, lack of speech, a decrease in alertness, drooling, difficulty controlling secretions and an absent gag reflex. (12)

Video Fluoroscopy Swallow Study_(VFSS). 
The VFSS was performed with collaboration between an OT and a radiologist in the fluoroscopy suite, using barium to label a variety of food stuffs: thin liquid, thick liquid, purees and solids as appropriate for the age and skill of the child. Due to personal involvement, the OT participating in the VFSS was not blinded to the prior CFE outcome. Children were scanned using a Siemens Axiom Iconos R200 Fluoroscopy system at a frame rate of 15 per second. Barium sulfate for suspension $98 \% \mathrm{w} / \mathrm{p}$ for oral use (E-Z-EM Canada) was diluted with food liquids and solids according to the child's capabilities. Radiation emission in MSv units was recorded, as an approximation due to variations in screening time and body surface area exposed.

Care was taken to simulate the child's natural feeding environment. The child was fed by their caregiver and positioned on a purpose-built adaptable chair, adjusted to mimic the usual feeding position (figure 1). Since nasogastric tubes impair swallowing, (13) they were removed prior to the examination. Pulsed serial x-rays of the oropharynx and esophagus were taken from a lateral view. The distal esophagus and stomach were included for assessment of reflux. To reduce radiation exposure, when the history suggested aspiration developing with fatigue, multiple swallows were initially performed without fluoroscopy using a safe substance, with a later repetition of fluoroscopic swallow using the highest risk substance.

An OT reviewed the prose VFSS report retroactively and scored it using the eight-point penetration-aspiration scale (table 1) for each fluid/ food consistency trialed. Children scoring 1 to 5 represented no aspiration (NA), and 6 to 8 represented oro-pharyngeal aspiration (OPA). Within OPA, a score of 6 or 7 was graded as overt aspiration, and 8 as silent aspiration (SA), i.e. detection of material below the level of the true vocal folds without cough or other laryngeal response within 20 seconds. (14) Silent aspiration (SA), as a score for CFE referred to "suspected silent aspiration". For both CFE and VFSS, children were classified as displaying "no", "overt" or "silent" aspiration based on the most pathological behavior encountered, "silent aspiration" being the most severe form. Thus, silent aspiration with any texture overrode overt aspiration as the classification, even when the latter occurred with another texture.

\section{Feeding interventions}

Following CFE, feeding interventions consisted of any combination of texture adaptation, interface adaptation, oromotor stimulation, positioning or a recommendation to remain on enteral feeds only. When more than one CFE was carried out, the assessment closest to the VFSS was used for comparison.

The mode of feeding recommended was noted following the CFE (pre -VFSS) and again post - VFSS. It was categorized as oral, mixed oral with nasogastric tube (NGT) or percutaneous endoscopic gastrostomy (PEG) supplements, or enteral (NGT or PEG) only. In defining changes in management, we simplified the scoring to "oral" for exclusively orally fed children and "enteral" for mixed and purely enterally fed children.

\section{Clinical status}

Medical records from the 12 months preceding and following the VFSS were reviewed to determine the number, nature and length of hospital admissions, primary care and emergency department visits and number of antibiotic courses prescribed.

\section{$\underline{\text { Statistics }}$}


Data were analyzed using SPSS, version 25 (SPSS Inc; Chicago, Illinois). Demographic factors, organ systems and medical diagnoses were summarized with percentage breakdown. For comparison of difference between two sub-groups, independent samples t-test was used when normal distribution was assumed, otherwise, a Mann-Whitney test was used. The findings of the CFE were compared with VFSS data using Fisher's exact test or Chi square test. Multivariate analysis for medical diagnoses was conducted using a logistic regression model. To determine the positive and negative predicted value of the CFE compared to VFSS, a fourfold table with Crosstabulation was used. Interrater agreement was measured using Cohen's Kappa coefficient. The McNemar $\mathrm{Chi}^{2}$ test was used to assess the change in feeding route following VFSS.

\section{Results}

\section{Study_population}

Of 128 children referred for VFSS, 113 performed it successfully (Figure 2). Median age was 2.2 years (range 0.1-17.9). Forty-six of $113(41 \%)$ had oropharyngeal aspiration, 9 (8\%) overt and 37 (33\%) silent, while 67 $(59 \%)$ showed no evidence of aspiration.

At the time of VFSS, 39 (35\%) children were fed enterally; 8 gastrostomy, 2 gastro-jejunal or naso-jejunal, 1 nasogastric, and 28 mixed oral and enteral. The remaining children were fed orally. No child had a tracheostomy.

Organ systems mainly affected, and medical diagnoses are shown in table 2. Most children, 98 out of 113 $(87 \%)$ had cardio-pulmonary involvement, with clinical aspiration lung disease in $87(77 \%)$ and congenital heart disease in 42 (37\%). The latter was associated with at least one other diagnosis in 39 out of 42 (93\%) cases. Frequent gastro-intestinal, $73(64 \%)$ and neurological involvement, $68(60 \%)$ indicated a high prevalence of complex developmental disorders, such as genetic syndromes and cerebral palsy, often resulting in dysphagia. The structural group included children with cleft palate, laryngeal cleft and tracheoesophageal fistula.

\section{Predictive value of clinical feeding evaluation}

A flow diagram including the results of CFE and VFSS is shown in figure 2. A normal VFSS was predicted by prior normal CFE in 51 out of $67(76 \%)$ cases. Abnormal VFSS included an element of silent aspiration in 37 out of $46(80 \%)$ children with aspiration. Although 31/37 (84\%), had a prior abnormal CFE, 18 of these 31 $(58 \%)$ had been classified as overt aspirators, possibly due to overt aspiration with some food textures while silent aspirations were missed. Of greatest concern, a total of 10 patients had been deemed free of aspiration according to CFE and later found to have abnormal VFSS (4 overt and 6 silent).

Considering VFSS as the gold standard for diagnosing aspiration, CFE demonstrated an overall sensitivity and specificity of $71 \%$ and $84 \%$ respectively (table 3 ), suggesting that the OT was fairly reliable in discerning pathology from normalcy. However, when overt and silent aspiration were considered separately, detection sensitivity fell markedly, as reflected by the low positive predicted value (PPV) of CFE for both overt and silent aspirations of $15 \%$ and $35 \%$ respectively, indicating a high number of false positive assessments. 
The aspiration status per VFSS, according to demographics, organ system involvement and medical diagnoses is shown in table 2. Throughout, overt aspirations were the least frequent finding, compared to no aspiration and silent aspiration. Only 1/22 infants under one year, showed overt aspiration alone on VFSS, whilst $10(45 \%)$ had silent aspirations. According to CFE for these 10, only three had suspected silent aspiration, five had overt aspirations alone and two had no aspirations.

The silent aspiration group had a high representation of neurological and genetic abnormalities, and particularly of clinically suspected aspiration pneumonias. Structural abnormalities were associated with the lowest rates of aspiration.

Figure 3 shows types of aspiration per texture trialed, as identified by VFSS. Among 113 children, 89 were evaluated with thin liquid, 70 with thick liquid, 60 with thin puree, 67 with thick puree and 47 with solids. For all consistencies, "no aspiration" was the most common, and "overt aspiration" the least common result. Of note, $25 / 70(36 \%)$ of subjects had silent aspiration with thick liquid. The fewest aspirations were noted with solids, with all $5 / 47(11 \%)$ showing silent aspirations.

A logistic regression model, relating medical diagnoses to the presence of aspiration (combined overt and silent), according to VFSS is shown in table 4. It shows that children with clinical aspiration lung disease and cerebral palsy were more prone to VFSS aspiration, with an OR of 3.2 and 9.8 respectively. These observations hold true following adjustment for age.

\section{Feeding interventions}

Following 101 out of $113 \mathrm{CFEs}$, the OT suggested changes in the way the child was fed, most frequently texture adaptation 89/ 113 (79\%), but also interface adaptation, oro-motor stimulation and positioning. Five children were instructed to stop oral feeds following CFE. Of these five, four had previously been exclusively orally fed and one on mixed feeds. The recommendation was sustained in two of those five children following VFSS, while it was found safe to resume oral feeding in the remaining three children. Following VFSS, 12 children were asked to stop oral feeding, only two having received that recommendation following CFE. Six had previously been exclusively orally fed and six mixed fed. Taking all feeding route recommendations post VFSS together, they differed significantly from those based on the preceding CFE, $p<0.001$. The rate of exclusively orally fed children rose from $65 \%$ to $79 \% ; p=0.006$ following VFSS, whilst the rate of exclusively enterally fed children also increased, from $10 \%$ to $14 \% ; p=0.005$.

\section{Clinical status 1 year pre vs 1 year post VFSS}

In the year following VFSS, there were significantly less total and respiratory related hospital admissions, and less antibiotic courses were administered, see table 5. Although the number of intensive care admissions also decreased, and community visits increased, neither of these reached statistical significance.

\section{Discussion}


In this retrospective cohort study, we found that CFE was not sufficiently reliable in recommending best feeding management in this group of children with marked respiratory morbidity and suspected aspiration. Our study is one of few that describes clinical outcomes following VFSS guided feeding interventions. $(3,4$, 7-9) Although there may be some spontaneous improvement, the significant decrease in hospitalizations and requirement for antibiotics following feeding interventions in this cohort is noteworthy.

A recent systematic review laments the lack of evidence on the accuracy of CFE in detecting aspirations in children. (15) Only four studies comparing CFE with VFSS were found suitable for inclusion, with heterogeneous patient characteristics. Sensitivity estimates varied widely, between 0.17 ( $95 \%$ confidence interval [Cl] 0.05-0.37) and $0.93(95 \% \mathrm{Cl} 0.76-0.99)$. Specificity estimates ranged from $0.00(95 \% \mathrm{Cl}, 0.00-$ $0.52)$ to 1.00 (95\% $\mathrm{Cl} 0.16-1.00)$. Discrepancies related largely to population differences. In our study, the majority of children had clinical aspiration lung disease, suggesting a sample with a high rate of sequelae.

Our findings of missed aspirations by CFE as well as incorrect feeding decisions, suggest that VFSS should be performed for all cases of significant pulmonary morbidity and suspected aspiration. The OT suspected silent aspirations on CFE based on indirect clues such as a wet voice, $(12,16)$ but missed over $20 \%$ of children with abnormal VFSS. Conversely, over $20 \%$ of those with normal VFSS were considered to have aspiration based on CFE. Nevertheless, as discrepancies may in part be due to the intermittent nature of aspiration, collaboration between the managing pulmonologist and the OT who reviews the child one or more times, remains essential in addition to VFSS. (17)

"No aspiration" was the most frequent finding on VFSS with all consistencies trialed. In this regard, VFSS provides important confirmation of safety for oral feeding. The paucity of overt aspiration alone detected by VFSS may reflect management of these cases following CFE alone as previously recommended (18) and their exclusion from this study. We suggest that in the future, VFSS could be beneficial even for such children.

Up to $90 \%$ of children with neurological and maturational disorders, e.g. Familial Dysautonomia or Down's syndrome have silent aspiration on VFSS. (19) In our population, too, these groups showed far more silent than overt aspirations.

Of infants under one year, a critical time in terms of oro-motor skill acquisition, $(20,21)$ almost half showed silent aspirations, whereas overt aspirations were rarely observed. Most had neurological and genetic abnormalities, as well as clinical aspiration pneumonias. In contrast, structural defects of the airway did not give rise to silent aspirations, as these children cough upon exposure to foreign material in the airway. (6)

The contribution of laryngeal penetration, remaining above the vocal cords, (22) to aspiration lung disease is debated. In a recent study, it appeared significant as subsequent thickening of feeds was associated with decreased symptoms and hospitalization. (23) Nevertheless, due to the inability of CFE to detect penetration, we simplified our classification and did not consider it as aspiration although children who were "caught" with penetrations on VFSS, may have aspirated on other occasions.

There are few reports on the outcome following VFSS guided feeding intervention. We have shown that children improved clinically across a number of domains in the year following such integrated feeding 
management. This is in keeping with a large recent retrospective cohort study in young infants showing that thickening feeds after observing silent aspirations on VFSS reduced the risk of acute respiratory infection.

$(23,24)$

Broader considerations including parental concerns and choices should be part of management decisions. (25) Feeding represents a key channel of communication which families are often reluctant to forsake, even knowing their child might be at risk of aspiration. Clinicians must be sensitive to this complex interaction. Our study was not designed to take these issues into consideration, but the first step is certainly an accurate diagnosis of the extent and nature of aspiration.

Bearing in mind our obligation to keep the radiation dose as low as reasonably achievable (ALARA), (26) VFSS was performed by intermittent screening, which risks missing penetration and aspiration events. Although VFSS radiation doses compare favorably with nuclear scintigraphy tests for aspiration such as a salivagram or milk scan, (27) it is expected that this will improve further, as has been described with lowdose digital pulsed video-fluoroscopic swallow exams. (28)

Our study has a number of limitations, in particular its retrospective design and lack of control group. Although we demonstrated clinical improvement following intervention, swallowing dysfunction does tend to improve with time and maturation. (21) However, this bias resulting from regression to the mean could not be assessed as a control group would clearly be unethical. Our cohort consisted exclusively of children referred to VFSS and not those managed by OT and CFE alone, providing a bias to more severe cases. Conversely, there was insufficient VFSS data on seven children due to poor co-operation, possibly skewing our cohort towards "milder" cases who could cooperate. A further limitation lies in the fact that children underwent CFE and VFSS on different occasions and each of these represent brief glimpses of a complex reality with intermittent aspirations occurring. This is exemplified by the finding that five patients with overt aspirations detected clinically, displayed only silent aspirations during VFSS.

To conclude, in our selected population of children with high prevalence of clinical aspiration lung disease, VFSS resulted in frequent change in feeding route compared to prior CFE alone with ensuant clinical improvement. We suggest to consider VFSS as part of an integrative approach to feeding management whenever aspiration is suspected.

\section{References}

1. Tutor JD, Gosa MM. Dysphagia and aspiration in children. Pediatr Pulmonol. 2012;47(4):321-37.

2. Schwarz SM, Corredor J, Fisher-Medina J, Cohen J, Rabinowitz S. Diagnosis and treatment of feeding disorders in children with developmental disabilities. Pediatrics. 2001;108(3):671-6.

3. Sheikh S, Allen E, Shell R, Hruschak J, Iram D, Castile R, et al. Chronic aspiration without gastroesophageal reflux as a cause of chronic respiratory symptoms in neurologically normal infants. Chest. 2001;120(4):1190-5.

4. Heuschkel RB, Fletcher K, Hill A, Buonomo C, Bousvaros A, Nurko S. Isolated neonatal swallowing dysfunction: a case series and review of the literature. Dig Dis Sci. 2003;48(1):30-5. 
5. Breton SMaS, editor. Infant and Child Feeding adn Swallowing. Bethesda, MD 20814: American Occupational Therapy Association, Inc. ; 2013.

6. Weir KA, McMahon S, Taylor S, Chang AB. Oropharyngeal aspiration and silent aspiration in children. Chest. 2011;140(3):589-97.

7. Duncan DR, Mitchell PD, Larson K, Rosen RL. Presenting Signs and Symptoms do not Predict Aspiration Risk in Children. J Pediatr. 2018;201:141-6.

8. Silva-Munhoz Lde F, Buhler KE, Limongi SC. Comparison between clinical and videofluoroscopic evaluation of swallowing in children with suspected dysphagia. Codas. 2015;27(2):186-92.

9. Burklow KA, Phelps AN, Schultz JR, McConnell K, Rudolph C. Classifying complex pediatric feeding disorders. J Pediatr Gastroenterol Nutr. 1998;27(2):143-7.

10. Rosenbek JC, Robbins JA, Roecker EB, Coyle JL, Wood JL. A penetration-aspiration scale. Dysphagia. 1996;11(2):93-8.

11. Robbins J, Coyle J, Rosenbek J, Roecker E, Wood J. Differentiation of normal and abnormal airway protection during swallowing using the penetration-aspiration scale. Dysphagia. 1999;14(4):228-32.

12. Garon BR, Sierzant T, Ormiston C. Silent aspiration: results of 2,000 video fluoroscopic evaluations. J Neurosci Nurs. 2009;41(4):178-85; quiz 86-7.

13. Alnassar M, Oudjhane K, Davila J. Nasogastric tubes and videofluoroscopic swallowing studies in children. Pediatr Radiol. 2011;41(3):317-21.

14. Arvedson J, Rogers B, Buck G, Smart P, Msall M. Silent aspiration prominent in children with dysphagia. Int J Pediatr Otorhinolaryngol. 1994;28(2-3):173-81.

15. Calvo I, Conway A, Henriques F, Walshe M. Diagnostic accuracy of the clinical feeding evaluation in detecting aspiration in children: a systematic review. Dev Med Child Neurol. 2016;58(6):541-53.

16. Rosenfeld M, Emerson J, Williams-Warren J, Pepe M, Smith A, Montgomery AB, et al. Defining a pulmonary exacerbation in cystic fibrosis. J Pediatr. 2001;139(3):359-65.

17. Boesch RP, Daines C, Willging JP, Kaul A, Cohen AP, Wood RE, et al. Advances in the diagnosis and management of chronic pulmonary aspiration in children. Eur Respir J. 2006;28(4):847-61.

18. Suiter DM, Leder SB, Karas DE. The 3-ounce (90-cc) water swallow challenge: a screening test for children with suspected oropharyngeal dysphagia. Otolaryngol Head Neck Surg. 2009;140(2):187-90.

19. Jackson A, Maybee J, Moran MK, Wolter-Warmerdam K, Hickey F. Clinical Characteristics of Dysphagia in Children with Down Syndrome. Dysphagia. 2016;31(5):663-71.

20. Sanchez K, Spittle AJ, Slattery JM, Morgan AT. Oromotor Feeding in Children Born Before 30 Weeks' Gestation and Term-Born Peers at 12 Months' Corrected Age. J Pediatr. 2016;178:113-8 e1.

21. Lau C. Development of Suck and Swallow Mechanisms in Infants. Ann Nutr Metab. 2015;66 Suppl 5:714.

22. Brodsky L. Dysphagia with respiratory/pulmonary presentation: assessment and management. Semin Speech Lang. 1997;18(1):13-22; quiz -3.

23. Duncan DR, Larson K, Davidson K, May K, Rahbar R, Rosen RL. Feeding Interventions Are Associated With Improved Outcomes in Children With Laryngeal Penetration. J Pediatr Gastroenterol Nutr. 
2019;68(2):218-24.

24. Coon ER, Srivastava R, Stoddard GJ, Reilly S, Maloney CG, Bratton SL. Infant Videofluoroscopic Swallow Study Testing, Swallowing Interventions, and Future Acute Respiratory Illness. Hosp Pediatr. 2016;6(12):707-13.

25. Arvedson JC. Assessment of pediatric dysphagia and feeding disorders: clinical and instrumental approaches. Dev Disabil Res Rev. 2008;14(2):118-27.

26. The 2007 Recommendations of the International Commission on Radiological Protection. ICRP publication 103. Ann ICRP. 2007;37(2-4):1-332.

27. Weir KA, McMahon SM, Long G, Bunch JA, Pandeya N, Coakley KS, et al. Radiation doses to children during modified barium swallow studies. Pediatr Radiol. 2007;37(3):283-90.

28. Weiss J, Notohamiprodjo M, Neumaier K, Li M, Flatz W, Nikolaou K, et al. Feasibility of low-dose digital pulsed video-fluoroscopic swallow exams (VFSE): effects on radiation dose and image quality. Acta Radiol. 2017;58(9):1037-44.

\section{Tables}

\section{Table 1:}

Eight-point penetration-aspiration scale, designed for video-fluoroscopy swallow studies and adapted for clinical assessment.

\begin{tabular}{|c|c|c|c|}
\hline Category & Score & Description (radiological) & $\begin{array}{l}\text { Description } \\
\text { (clinical) }\end{array}$ \\
\hline $\begin{array}{l}\text { No penetration or } \\
\text { aspiration }\end{array}$ & 1 & Contrast does not enter the airway & No aspiration \\
\hline \multirow[t]{4}{*}{ Penetration } & 2 & $\begin{array}{l}\text { Contrast enters the airway, remains above vocal } \\
\text { folds, no residue }\end{array}$ & \\
\hline & 3 & $\begin{array}{l}\text { Contrast remains above vocal folds, visible residue } \\
\text { remains }\end{array}$ & \\
\hline & 4 & Contrast contacts vocal folds, no residue & \\
\hline & 5 & $\begin{array}{l}\text { Contrast contacts vocal folds, visible residue } \\
\text { remains }\end{array}$ & \\
\hline \multirow[t]{3}{*}{ Aspiration } & 6 & $\begin{array}{l}\text { Contrast passes glottis, no sub-glottic residue } \\
\text { visible }\end{array}$ & Overt aspiration \\
\hline & 7 & $\begin{array}{l}\text { Contrast passes glottis, visible sub-glottic residue } \\
\text { despite patient's response }\end{array}$ & \\
\hline & 8 & $\begin{array}{l}\text { Contrast passes glottis, visible sub-glottic residue, } \\
\text { absent patient response }\end{array}$ & $\begin{array}{l}\text { Suspected silent } \\
\text { aspiration }\end{array}$ \\
\hline
\end{tabular}

\section{Table 2:}


Aspiration status according to videofluoroscopy swallow study per patient, according to organ systems and medical diagnoses. The little letter a indicates percentages of categories for the entire group, not mutually exclusive. Little letter $b$ indicates the percentage of categories (demographics/ organ systems/ medical diagnoses) represented in each of the three aspiration modes (no aspiration, overt aspiration and silent aspiration); e.g. out of 67 children that did not aspirate, 32 (48\%) had neurological abnormalities, $41(61 \%) \mathrm{GI}$ abnormalities, etc. The little letter $\mathrm{c}$ indicates percentage of aspiration status relative to category; e.g. 32 out of $68(47 \%)$ of all children with neurological problems did not aspirate, $5(7 \%)$ and 31 (46\%) showed overt and silent aspirations respectively. 


\begin{tabular}{|c|c|c|c|c|c|c|c|c|c|c|c|}
\hline \multirow[t]{2}{*}{ Category } & \multicolumn{2}{|l|}{ Total } & \multicolumn{3}{|c|}{ No aspiration } & \multicolumn{3}{|c|}{ Overt aspiration } & \multicolumn{3}{|c|}{ Silent aspiration } \\
\hline & $n=113$ & $\%^{a}$ & $n=67$ & $\%^{b}$ & $\%^{c}$ & $n=9$ & $\%^{b}$ & $\%^{\mathrm{c}}$ & $n=37$ & $\%^{b}$ & $\%^{\mathrm{c}}$ \\
\hline \multicolumn{12}{|l|}{ Demographics } \\
\hline Age $\leq 1$ & 22 & $20 \%$ & 11 & $16 \%$ & $50 \%$ & 1 & $11 \%$ & $5 \%$ & 10 & $27 \%$ & $45 \%$ \\
\hline Age $>1$ & 91 & $80 \%$ & 56 & $84 \%$ & $61 \%$ & 8 & $89 \%$ & $9 \%$ & 27 & $73 \%$ & $30 \%$ \\
\hline Male & 67 & $61 \%$ & 43 & $64 \%$ & $63 \%$ & 6 & $67 \%$ & $10 \%$ & 18 & $49 \%$ & $27 \%$ \\
\hline Female & 46 & $39 \%$ & 24 & $36 \%$ & $53 \%$ & 3 & $33 \%$ & $6 \%$ & 19 & $51 \%$ & $41 \%$ \\
\hline \multicolumn{12}{|l|}{ Organ System } \\
\hline Neurology & 68 & $68 \%$ & 32 & $48 \%$ & $47 \%$ & 5 & $56 \%$ & $7 \%$ & 31 & \multirow{2}{*}{$\begin{array}{l}84 \% \\
68 \%\end{array}$} & $46 \%$ \\
\hline GI & 73 & $64 \%$ & 41 & $61 \%$ & $56 \%$ & 7 & $78 \%$ & $9 \%$ & 25 & & $35 \%$ \\
\hline Cardinnulmonan & 98 & $87 \%$ & 55 & $82 \%$ & $56 \%$ & 7 & $78 \%$ & $7 \%$ & 36 & \multirow{3}{*}{$\begin{array}{l}97 \% \\
43 \% \\
8 \%\end{array}$} & $37 \%$ \\
\hline 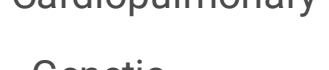 & 36 & $32 \%$ & 19 & $28 \%$ & $53 \%$ & 1 & $11 \%$ & $3 \%$ & 16 & & $44 \%$ \\
\hline Structural & 18 & $16 \%$ & 15 & $22 \%$ & $83 \%$ & 0 & $0 \%$ & $0 \%$ & 3 & & $17 \%$ \\
\hline \multicolumn{12}{|l|}{$\begin{array}{l}\text { Medical } \\
\text { Diagnoses }\end{array}$} \\
\hline Down's & 14 & $12 \%$ & 7 & $10 \%$ & $50 \%$ & 1 & $11 \%$ & $7 \%$ & 6 & $16 \%$ & $43 \%$ \\
\hline Syndrome & 21 & $19 \%$ & 6 & $9 \%$ & $29 \%$ & 4 & $44 \%$ & $19 \%$ & 11 & $30 \%$ & $52 \%$ \\
\hline $\mathrm{CP}$ & 37 & $32 \%$ & 18 & $26 \%$ & $49 \%$ & 5 & $56 \%$ & $13 \%$ & 14 & $37 \%$ & $38 \%$ \\
\hline Dev delay & 42 & $37 \%$ & 24 & $15 \%$ & $57 \%$ & 3 & $33 \%$ & $7 \%$ & 15 & $41 \%$ & $36 \%$ \\
\hline Congenital & 16 & $14 \%$ & 10 & $69 \%$ & $63 \%$ & 1 & $11 \%$ & $6 \%$ & 5 & $14 \%$ & $31 \%$ \\
\hline & 87 & $78 \%$ & 46 & $3 \%$ & $53 \%$ & 6 & $67 \%$ & $7 \%$ & 35 & $95 \%$ & $40 \%$ \\
\hline $\begin{array}{l}\text { Preterm <3/ } \\
\text { weeks }\end{array}$ & 3 & $3 \%$ & 2 & & $67 \%$ & 0 & $0 \%$ & $0 \%$ & 1 & $3 \%$ & $33 \%$ \\
\hline \multicolumn{12}{|l|}{$\begin{array}{l}\text { Aspiration lung } \\
\text { ds }\end{array}$} \\
\hline BPD & & & & & & & & & & & \\
\hline
\end{tabular}

$\mathrm{GI}=$ gastro-intestinal; $\mathrm{CP}=$ cerebral palsy; $\mathrm{Dev}$ delay= developmental delay; $\mathrm{BPD}=$ broncho-pulmonary dysplasia.

a Percentage of total group

${ }^{b}$ Percentage of category relative to aspiration status

${ }^{\mathrm{c}}$ Percentage of aspiration status relative to category 


\section{Table 3:}

Predictive value of clinical feeding evaluation for video-fluoroscopic swallow study outcome

\begin{tabular}{|lllll|}
\hline & All Aspirations & Overt Aspiration & Silent Aspiration & No aspiration \\
\hline Sensitivity & $71 \%$ & $56 \%$ & $77 \%$ & $78 \%$ \\
\hline Specificity & $84 \%$ & $72 \%$ & $75 \%$ & $78 \%$ \\
\hline PPV & $78 \%$ & $15 \%$ & $35 \%$ & $71 \%$ \\
\hline NPV & $78 \%$ & $95 \%$ & $95 \%$ & $84 \%$ \\
\hline
\end{tabular}

\section{Table 4:}

Logistic regression model describing the relationship between medical diagnoses and the presence of aspiration (combined overt and silent), according to VFSS.

\begin{tabular}{|lllllll|}
\hline p value & $95 \% \mathrm{Cl}$ & AOR & p value & $95 \% \mathrm{Cl}$ & OR & Medical diagnoses \\
\hline 0.002 & $2.27-45.95$ & $10.2^{\star}$ & 0.002 & $2.2-42.8$ & $9.8^{*}$ & $\mathrm{CP}$ \\
\hline 0.008 & $1.82-12.7$ & $3.3^{\star}$ & 0.009 & $1.4-12.4$ & $3.2^{\star}$ & Aspiration lung disease \\
\hline 0.351 & $0.58-4.65$ & 1.64 & 0.3 & $0.6-4.9$ & 1.8 & Developmental delay \\
\hline 0.444 & $0.47-5.53$ & 1.61 & 0.4 & $0.5-5.7$ & 1.7 & Congenital heart disease \\
\hline 0.115 & $0.04-1.41$ & 0.24 & 0.1 & $0.04-1.5$ & 0.2 & Preterm <37 weeks \\
\hline 0.755 & $0.15-3.88$ & 0.77 & 0.7 & $0.2-3.9$ & 0.8 & Down's Syndrome \\
\hline 0.741 & $0.23-14.9$ & 0.59 & 0.7 & $0.02-14.6$ & 0.6 & BPD \\
\hline
\end{tabular}

$\mathrm{OR}=$ odds ratio; $\mathrm{Cl}=$ confidence interval; $\mathrm{AOR}=$ age adjusted odds ratio; $\mathrm{CP}=$ cerebral palsy; $\mathrm{BPD}=$ bronchopulmonary dysplasia.

*= Significant at $p<0.05$

\section{Table 5:}

Clinical outcomes 1 year pre vs 1 year post VFSS, per patient $(n=113)$. Values displayed as mean (SD). 


\begin{tabular}{|llll|}
\hline Outcome & Year Pre VFSS & Year Post VFSS & p-value \\
\hline Total no of admissions & $3.42(3.42)$ & $2.33(2.59)$ & $<0.001$ \\
\hline No of urgent admissions & $2.05(2.1)$ & $1.12(1.05)$ & $<0.001$ \\
\hline Total days of admission & $20.92(13.66)$ & $9.78(7.54)$ & $<0.001$ \\
\hline Respiratory admissions & $1.54(0.87)$ & $0.97(0.66)$ & 0.04 \\
\hline Intensive care admissions & $0.28(0.18)$ & $0.19(0.09)$ & N/S \\
\hline Total community visits & $14.64(9.65)$ & $16.49(10.46)$ & $\mathrm{N} / \mathrm{S}$ \\
\hline Respiratory community visits & $2.44(2.27)$ & $2.3(2.02)$ & $\mathrm{N} / \mathrm{S}$ \\
\hline Emergency room visits & $3.69(3.24)$ & $3.12(2.86)$ & $\mathrm{N} / \mathrm{S}$ \\
\hline Antibiotic courses & $2.88(2.56)$ & $1.8(0.89)$ & $<0.001$ \\
\hline
\end{tabular}

\section{Figures}






Figure 1

Care was taken to simulate the child's natural feeding environment. The child was fed by their caregiver and positioned on a purpose-built adaptable chair, adjusted to mimic the usual feeding position (figure 1). Since nasogastric tubes impair swallowing, (13) they were removed prior to the examination. Pulsed serial x-rays of the oropharynx and esophagus were taken from a lateral view. The distal esophagus and stomach were included for assessment of reflux. To reduce radiation exposure, when the history suggested aspiration 
developing with fatigue, multiple swallows were initially performed without fluoroscopy using a safe substance, with a later repetition of fluoroscopic swallow using the highest risk substance.

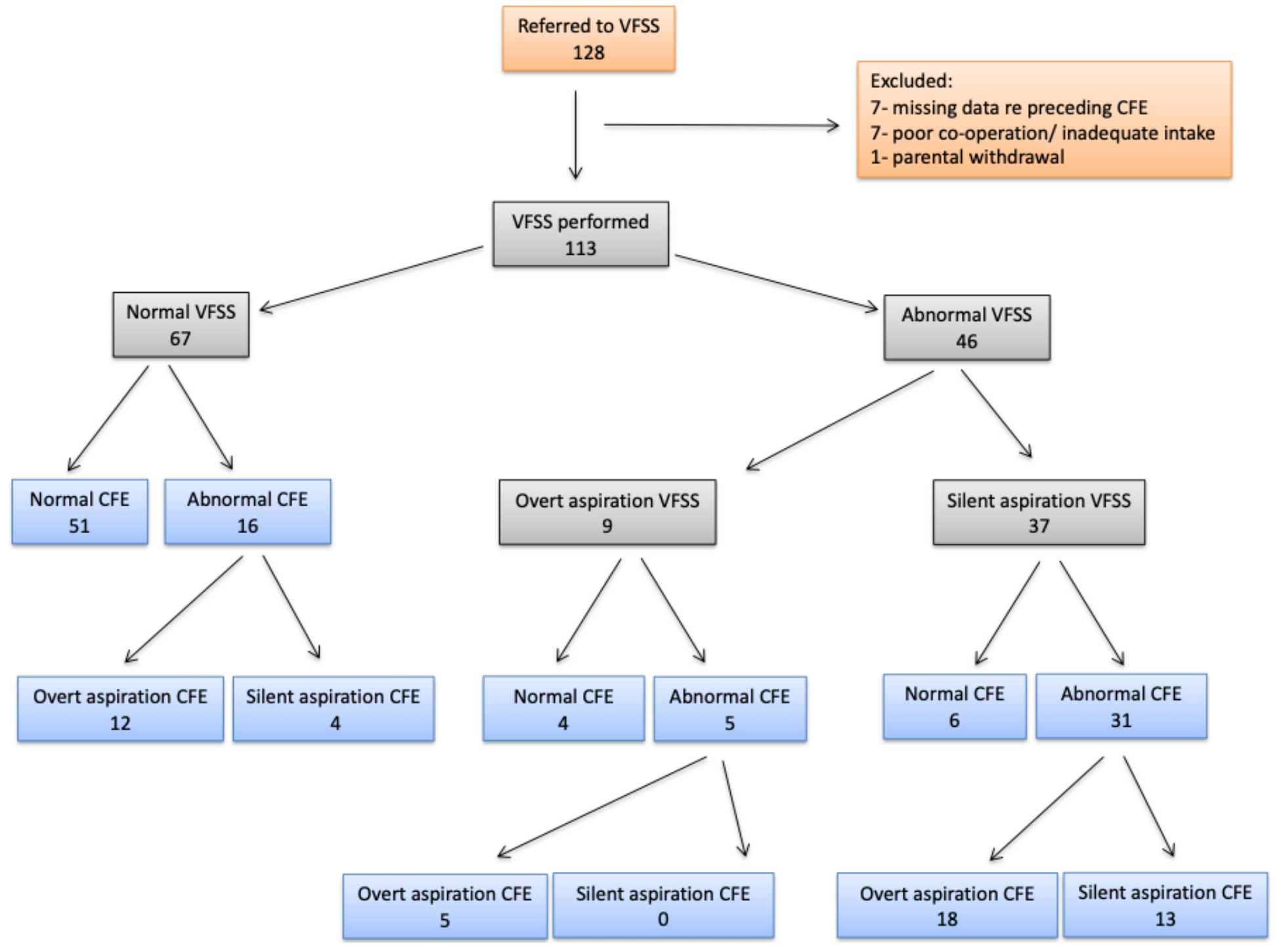

Figure 2

A flow diagram including the results of CFE and VFSS is shown in figure 2. A normal VFSS was predicted by prior normal CFE in 51 out of 67 (76\%) cases. Abnormal VFSS included an element of silent aspiration in 37 out of $46(80 \%)$ children with aspiration. Although 31/37 (84\%), had a prior abnormal CFE, 18 of these 31 $(58 \%)$ had been classified as overt aspirators, possibly due to overt aspiration with some food textures while silent aspirations were missed. Of greatest concern, a total of 10 patients had been deemed free of aspiration according to CFE and later found to have abnormal VFSS (4 overt and 6 silent). 


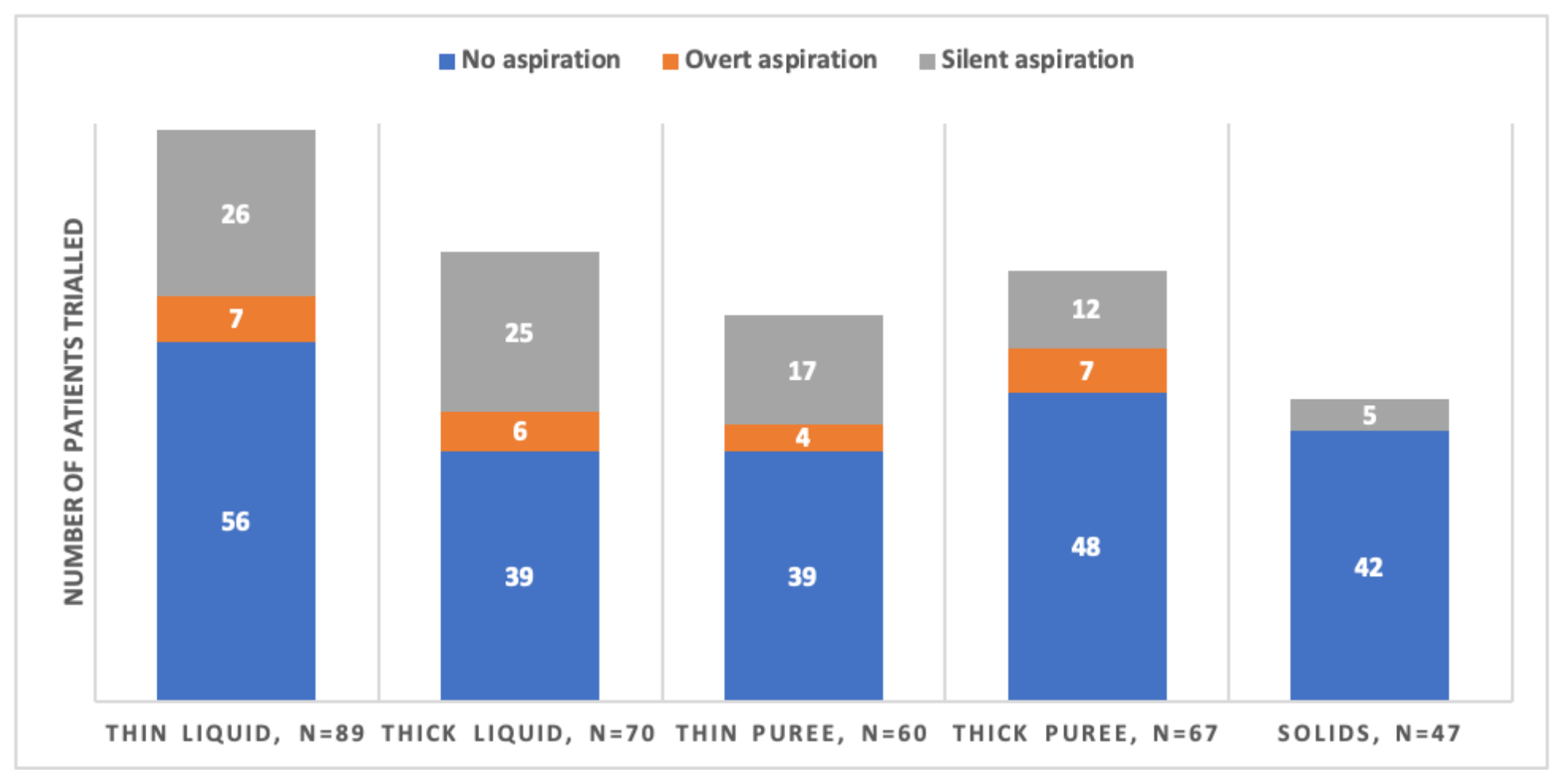

\section{Figure 3}

Figure 3 shows types of aspiration per texture trialed, as identified by VFSS. Among 113 children, 89 were evaluated with thin liquid, 70 with thick liquid, 60 with thin puree, 67 with thick puree and 47 with solids. For all consistencies, "no aspiration" was the most common, and "overt aspiration" the least common result. Of note, $25 / 70(36 \%)$ of subjects had silent aspiration with thick liquid. The fewest aspirations were noted with solids, with all $5 / 47(11 \%)$ showing silent aspirations. 